\title{
TERRA FLEXIBLE BLANKET SOLAR ARRAY DEPLOYMENT, ON-ORBIT PERFORMANCE AND FUTURE APPLICATIONS
}

\author{
Richard Kurland, Hans Schurig, Mark Rosenfeld and Michael Herriage \\ TRW Space and Electronics Group; Redondo Beach, California 90278 \\ Edward Gaddy and Denriny Keys \\ NASA/Goddard Space Flight Center; Grénbelt, Maryland 20771 \\ Carl Faust and William Andiario \\ Lockheed Martin Missiles and Space/Nalley Forge; King of Prussia, Pennsylvania 19101 \\ Michelle Kurtz and Eric Moyer \\ Lockheed Martin Space Operations \\ Mission Engineering and Ground Operations; Seabrook, Maryland 20706
}

\begin{abstract}
The Terra spacecraft (formerly identified as EOS AM1) is the flagship in a planned series of NASAVSFC Earth observing system satellites designed to provide information on the health of the Earth's land, oceans, air, ice, and life as a total ecological global system. It has been successfully performing its mission since a late-December 1999 launch into a $705 \mathrm{~km}$ polar orbit. The spacecraft is powered by a single wing, flexible blanket array using single junction (SJ) gallium arsenide/ germanium (GaAs/Ge) solar cells sized to provide 5 year end-of-life (EOL) power of greater than $5000 \mathrm{~W}$ at 127 Volts. It is currently the highest voltage and power operational flexible blanket array with GaAs/Ge cells. This paper briefly describes the wing design as a basis for discussing the operation of the electronics and mechanisms used to achieve successful on-orbit deployment. Its orbital electrical performance to date will be presented and compared to analytical predictions based on ground qualification testing. The paper concludes with a brief section on future applications and performance trends using advanced multi-junction cells and weight-efficient mechanical components.
\end{abstract}

\section{CONFIGURATION}

The solar array wing was designed, developed, and built by TRW Space \& Electronics Group under contract to Lockheed Martin Missiles and Space/Valley Forge (LMMSNF) for NASAGSFC. A complete description of the wing electrical and mechanical components has been detailed in several previous technical papers [1] - [3]. For this reason, only the main features will be briefly described as reference to the rest of the paper.

Figures 1 and 2 illustrate the deployed and stowed one wing array. Figures 3 and 4 show the flight wing supported on a special neutral buoyancy deployment test

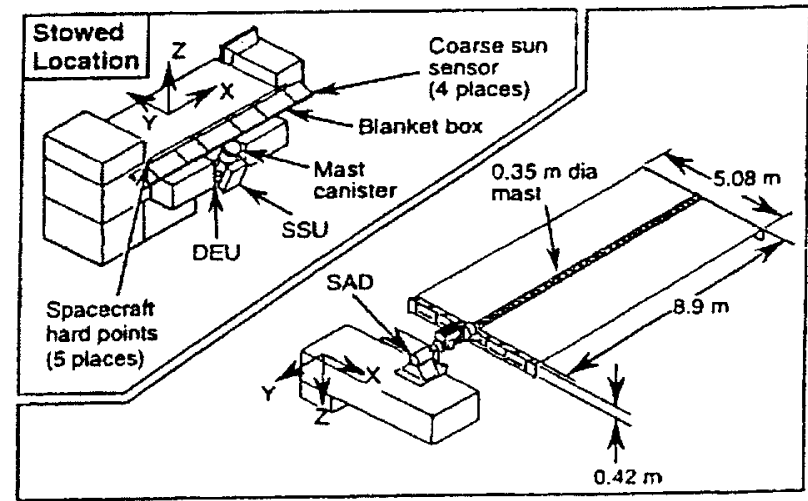

Fig. 1. Stowed Location/Deployed Array Size

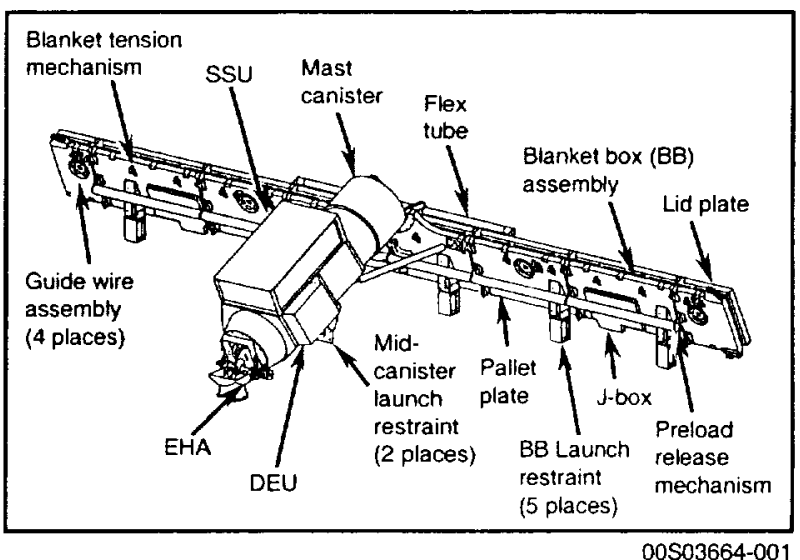

Fig. 2. Stowed Wing Configuration

fixture. The overall blanket area is $45 \mathrm{~m}^{2}$ and consist of eight 3-panel units covered with solar cell circuits and one instrumentation panel each on the outboard and inboard ends (Figures 5 and 6). Electrically, the blanket is divided into 24 circuits with each circuit consisting of eight parallel 


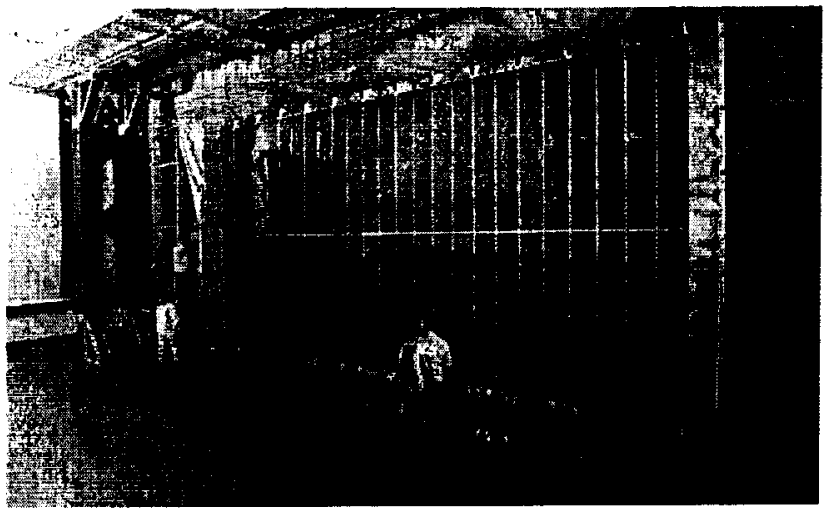

Fig. 3. Flight Wing (Front View)

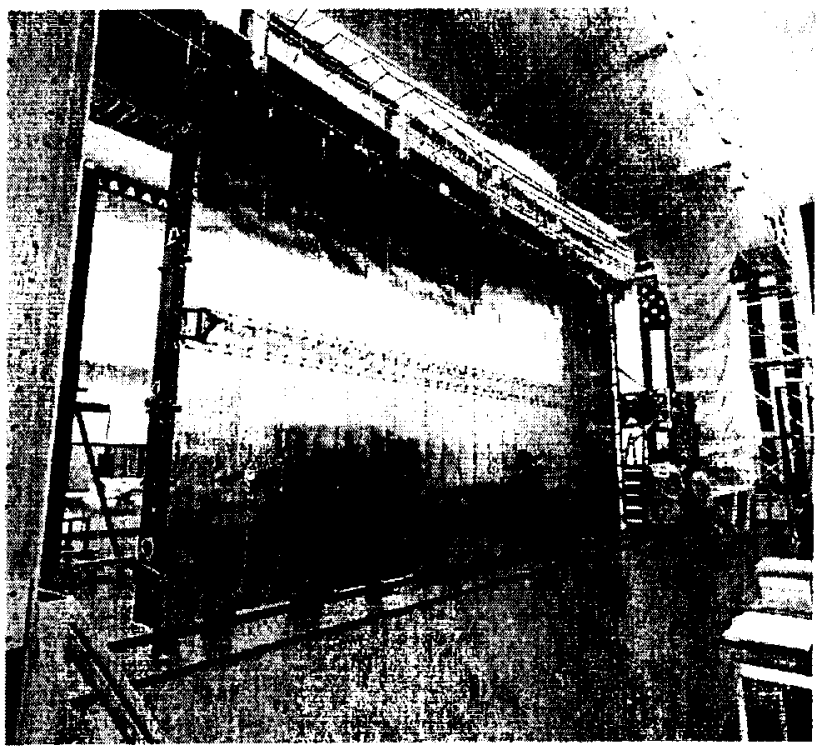

Fig. 4. Flight Wing (Rear View)

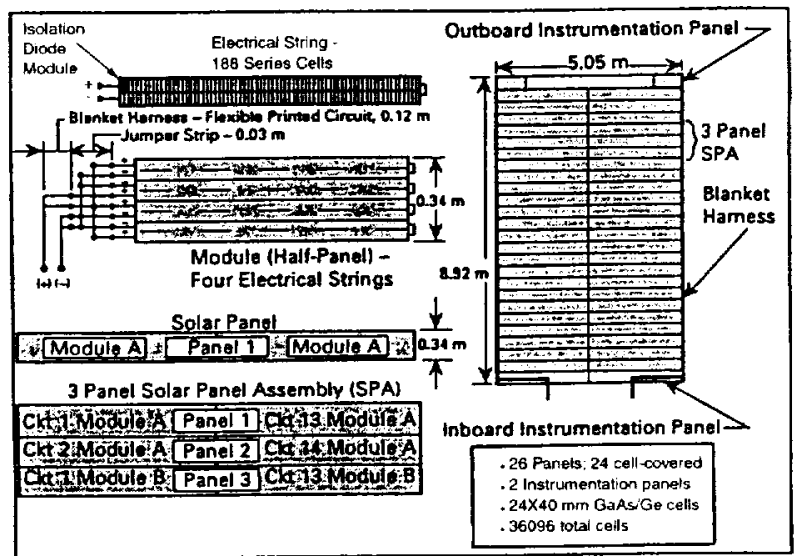

Fig. 5. Blanket/Circuit Configuration

strings. Each string doubles back on itself over half the blanket width to minimize current-generated magnetic moments. The originally manufactured design for the electrical circuits was retrofitted with special isolation diodes for each solar cell string to protect the circuits from

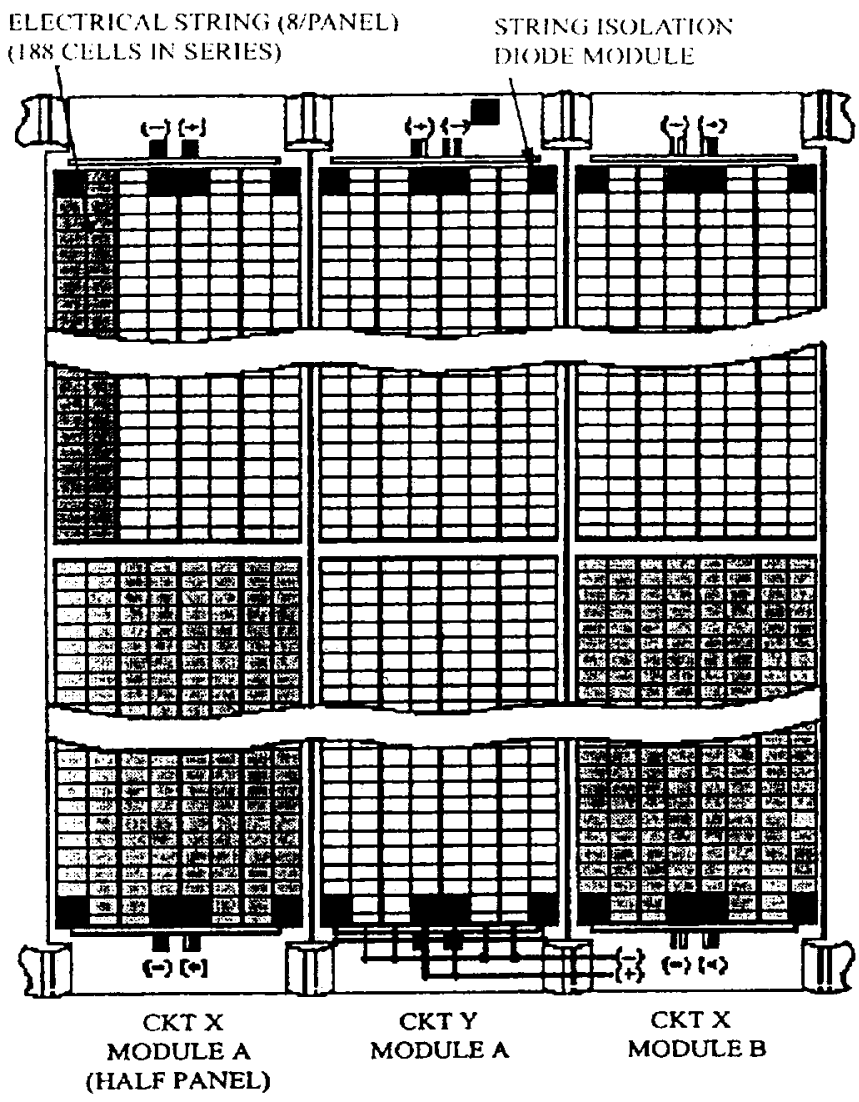

Fig. 6. Three-Panel Blanket Assembly Unit

electrostatic discharge initiated damage that is applicable to high voltage arrays above 60 Volts and 0.75 Amps [4], [5]. Thus, for the flight design, each string consists of 188 cells in series for a total of 36,096 TECSTAR $18.3 \%$, SJ GaAs/Ge cells, $24 \times 40 \times 0.14 \mathrm{~mm}$ in size. A flexible printed circuit harness $(-120 \mathrm{~mm}$ wide) runs along the two long longitudinal blanket edges routing the power and telemetry data from the solar cell circuits and blanket instrumentation ( $V_{o c}$ and $I_{s c}$ sensors and thermistors) to junction boxes located on the bottom side of the blanket box pallet structure.

The spacecraft switches the twenty-four circuits off and on depending on spacecraft power demands. Generally, one of the circuits is transmitting a fractional portion of its available output allowing the spacecraft to obtain precisely the power it requires. Spacecraft telemetry supplies the number of circuits transmitting and the current the array produces. The telemetry does not specify to what degree the partially transmitting section is turned on, only that it is transmitting. As seen later, this results in significant uncertainty in the array on orbit performance.

For launch, the blanket assembly is accordion-folded (343 $\mathrm{mm}$ hingeline spacing per panel) and stored/ protected in a blanket box $(\mathrm{BB})$. The blanket is folded with only cushioning foam material on the interior surface of the BB lid and pallet plate structures compressed to about $7000 \mathrm{~Pa}$ stowage pressure. The stowage pressure is 


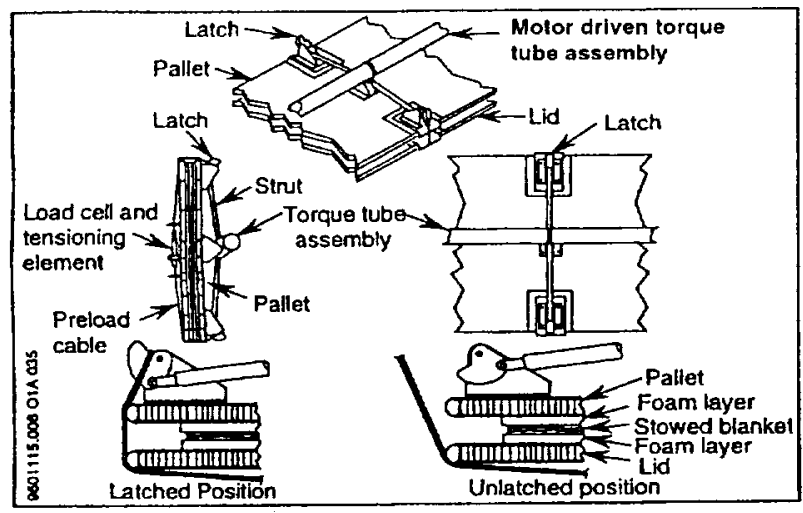

Fig. 7. Stowed Blanket Pre-Load Mechanism

applied and released through activation of a torque tube/ cable latch system that is installed on the outer surface of the BB lid and pallet plates (Figure 7). The mechanism has six cable/latch pairs that are simultaneously activated (unlatched) by a centrally-located 50 Volt, dual-wound, three phase, DC, brushless motor located on the underside of the BB pallet plate. There are Hall-effect position sensors embedded in the motor to provide pivot rate telemetry and primary/redundant limit switches incorporated into the motor installation hardware to indicate successful completion of unlatching operations. Total unlatching time is about 0.5 minute.

An electric motor-driven, canister-stowed, $350 \mathrm{~mm}$ diameter, continuous tri-longeron lattice mast (from AECAble) deploys the folded blanket assembly. A 100 Volt three phase, DC, brushless, mechanically redundant motor pair, driving through a planetary gearhead, extends the mast. There are Hall-effect position sensors embedded in each motor to provide mast extension rate telemetry and three pairs of primary/redundant limit switches located in the mast canister to indicate successful full length mast extension. Integral to each motor is a power-off brake. One motor is sufficient to deploy the mast. At full mast deployment, constant force springs at the interface between inboard/outboard blanket edges and the BB pallet/lid plates become extended to tension the blanket in the longitudinal direction to satisfy on-orbit wing-level deployed frequency $(>0.16 \mathrm{~Hz})$ and $0.015 \mathrm{~g}$ design limit load orbit-adjust requirements. Total time for full mast extension of about $9000 \mathrm{~mm}$ and blanket tensioning is about 10 minutes.

At the inboard end of the mast canister is an elevation hinge assembly (EHA). The EHA attaches to the outboard face of the LMMS solar array drive (SAD)/power transfer assembly. The EHA provides first stage deployment of the wing following near-simultaneous release of seven low shock, non-explosive actuator (NEA) pre-load bolts (five located on the BB pallet plate and two at the mid-region of the mast canister). The NEAs are powered directly from the spacecraft on a 28 -Volt secondary bus. Deployment energy for the EHA is provided by a spring/cable system with rate controlled by a passive eddy-current damper. Instrumentation on the EHA includes primary/redundant potentiometers to monitor EHA pivot position and primary/ redundant limit switches to indicate completion of first stage deployment and latch-up of the deployed EHA. The EHA pivots the wing 67 degrees to a position where the axis of the mast canister is aligned with the SAD axis of rotation and latches-up in about 1.5 to 3 minutes, depending on temperature conditions.

Controlling and monitoring all wing deployment operations, in response to commands from the LMMSsupplied Sequential Shunt Unit (SSU), is a deployment electronics unit (DEU) (Table 1). Within a $300 \times 230 \times 100$ $\mathrm{mm}, 5.4 \mathrm{~kg}$, common box structure are two identical subassemblies (prime and redundant) that share a common mechanical interface but are electrically isolated from each other. Each half of the DEU receives 120 Volts from the SSU and converts it into +5 and $\pm 15 V$ using a DC/DC converter supplied by Crane Interpoint. The DEU also receives twelve relay pulse commands from the SSU for controlling DC/DC converter operation, motor selection and direction, motor operation, and deployment limit switch override functions. The DEU acquires and conditions deployment status signals from the wing's redundant electromechanical limit switches, position potentiometers, motor temperalure sensors, and motor Hall Effect sensors for readout by the SSU.

\section{Table 1. DEU Command/Control Functions}

- $300 \times 230 \times 100 \mathrm{~mm}, 5.4 \mathrm{~kg}$, fully redundant, $120 \mathrm{Vdc}$ electronics package with passive thermal control

- Controls all deployment operations (except NEA release firings) through commands coming from spacecraft/SSU

- DEU enable/disable

- Select box motor or mast motor (primary or redundant side)

- Motor start/stops; forward/reverse

- Mast motor end-of-deployment sensor override (enable/disable)

Mast motor inhibit (enable/disable)

- Monitors deployment telemetry status

- EHA rotation position and latchup sensors (primary/redundant)

- Box unlatching sensors (primary/redundant)

- Mast rate-of-deployment sensors (primary/redundant)

- Mast end-of-deployment sensors (primary/redundant)

Mast motor inhibit override enable/disable Mast end-of-deployment sensors override status Mast motor temperature sensors

The DEU contains two interlock functions that prevent: (1) mast deployment motor operation prior to blanket box separation, and (2) mast deployment motor operation after the mast end-of-deployment limit switch has actuated. However, both functions can be overridden via ground command. The DEU also contains protection circuitry that removes power from the mast deployment motor in the event of a stall condition. All control functions are implemented using Actel 1020A Field Programmable Gate Arrays to minimize part count and maximize reliability. 
Each half of the DEU provides drive signals to the blanket box unlatching or mast deployment motor using a conventional 3-phase driver that is relay switched between motors in response to SSU commands. Thus, only one motor can operate at a time. The driver consists of three transformer isolated MOSFET half-bridges that are pulse width modulated at $40.75 \mathrm{kHz}$; a fourth half-bridge is used to energize the mast deployment motor's integral poweroff armature brake to ensure the brake is released prior to energizing the motor.

\section{ON ORBIT DEPLOYMENT OPERATIONS}

Terra was launched 18 December 1999. Approximately 20 minutes after spacecraft liftoff and orbit insertion, via an Atlas 2AS, both sides of the DEU were enabled to allow simultaneous monitoring of prime and redundant deployment telemetry signals. Thereafter, all deployment operations, including contingency actions, were placed under spacecraft computer control. During the first phase of deployment, after successful release of the seven NEAs, the EHA rotated 67 degrees and latchedup without incident. This first phase deployment lasted about 2 minutes during which time prime and redundant EHA position and latchup telemetry signals registered as expected. Deployment took place in the sunlit portion of the orbit.

During the second phase of deployment (also in the sunlit portion of the orbit) blanket box unlatching, using the primary side DEU, was initiated and completed in about 30 seconds. At the end of the unlatching, however, the blanket box status primary limit switch telemetry failed to indicate successful unlatching, although redundant telemetry indicated otherwise. During the third phase of deployment, commands were issued to the prime DEU to select and energize the mast deployment motor. The motor failed to respond because the prime side DEU's mast motor inhibit circuit prevents motor operation unless the blanket box status primary limit switch telemetry indicates successful unlatching. Since the redundant telemetry appeared normal, the spacecraft computer automatically transferred mast deployment operations to the redundant side DEU. Thereafter, mast deployment immediately started and proceeded normally at the rate of about $15 \mathrm{~mm} / \mathrm{second}$ for about 10 minutes, after which time the mast end-ofdeployment limit switches actuated and the motor turnedoff as expected. Thus, less than 50 minutes after liftoff, within the first orbit, the solar array was fully deployed.

Mast deployment and blanket unfolding began in the sunlit portion of the orbit, with sun on the rear side of the blanket, but was completed while in eclipse. However, sunlight reflecting off the Antarctic ice cap energized the deploying blanket solar cell circuits, indicating power generation from the wing. During the remainder of the eclipse, following completion of wing deployment, the spacecraft $S A D$ re-oriented the wing such that when coming out of the eclipse, the cell side of the wing began tracking the sun and generating power.

\section{ON-ORBIT POWER VS. PREDICTION}

To compare to predicted power, the on-orbit solar array performance is normalized to pre-launch performance under standard test conditions, which is shown in Figure 8. The "bumpy" character in the constant voltage side of the curve is due to slight voltage differences in the twenty-four sections comprising the array. The curve itself was obtained by measuring the output of each section and then combining them.

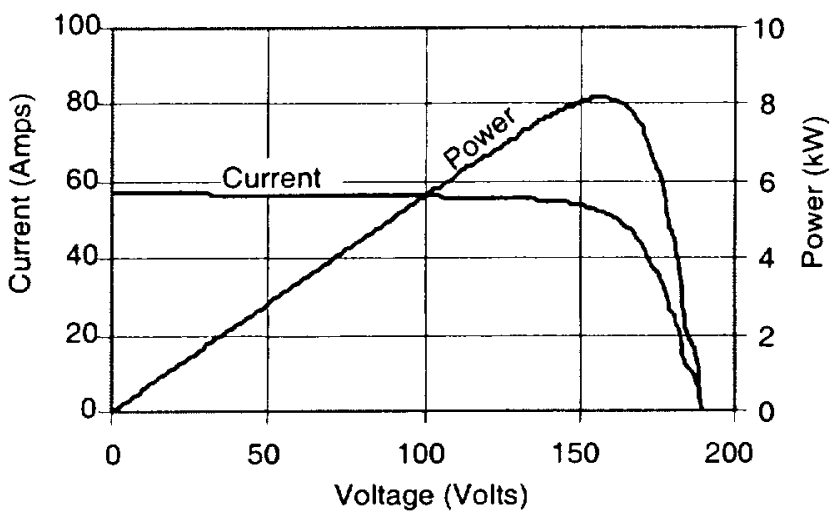

Fig. 8. Terra Solar Array Output Under Standard Test Conditions

Changes due to charged particle radiation damage, ultraviolet radiation, thermal cycling, micrometeoroids, seasonal variation, temperature, and angle between the sun-line and the array are used to normalize the on orbit telemetry to the test condition $1-\mathrm{V}$ characteristic. Design tactors for beginning-of-life (BOL) and end-of-life (EOL) predictions for these changes, which were specified by the spacecraft prime contractor (LMMS/VF), are given in Table 2. Cell mismatch does not appear in Table 2 because we are comparing the output of assembled panels which already include the effects of cell mismatch. The calibration error is taken out in our work in this paper by assuming unity.

Table 2. Power Analysis Design Factors Summary

\begin{tabular}{|l|c|c|c|}
\hline \multicolumn{1}{|c|}{ Characteristic } & Test & BOL & EOL \\
\hline Calibration Error & 0.98 & 1.02 & .98 \\
\hline UV Adhesive Darkening & 1.0 & 1.0 & .975 \\
\hline Radiation Cover Darkening & 1.0 & 1.0 & .995 \\
\hline Micrometeoroids & 1.0 & 1.0 & .98 \\
\hline Torsional Off-Pointing & $0^{\circ}$ & $0^{\circ}$ & $10^{\circ}$ \\
\hline Planar Off-Pointing & $0^{\circ}$ & $0^{\circ}$ & $1^{\circ}$ \\
\hline Plasma Loss & 1.0 & 1.0 & .99 \\
\hline Cell Radiation Losses & 1.0 & 1.0 & .922 \\
\hline Uncertainty & 1.0 & 1.0 & 1.0 \\
\hline Reliability & 1.0 & 1.0 & .948 \\
\hline Temperature Cycling Fatigue & 1.0 & 1.0 & 1.0 \\
\hline
\end{tabular}


Table 2 shows the UV darkening to be 0.975 and the cover darkening due to charged particle radiation to be 0.995 ; both at the EOL. The combined darkening is 0.970 . The actual amount of ultraviolet degradation and cover darkening is uncertain due to difficulties in test and in measuring on orbit degradation on earlier spacecraft. How this degradation occurs as a function of time is even more uncertain [6]. We have therefore somewhat arbitrarily assumed degradation in accordance with Figure 9, which uses equation (1), whereas $D$ represents days-in-orbit:

Transmittance $=1-0.00398^{\star} \operatorname{Ln}(D)$.

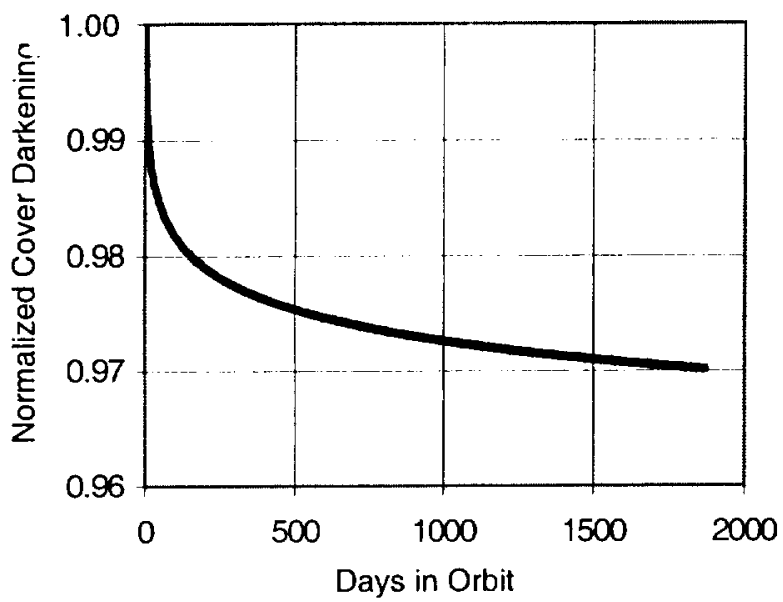

Fig. 9. Degradation Predicted to Solar Array Current As a Result of UV and Charged Particle Induced Cover Glass Darkening

The constant, -0.00398 , in equation (1) forces the transmittance to 0.970 if days in orbit equals 1826 or five years. This degradation roughly corresponds to TRW UV test results to 1,000 equivalent sun hours. The degradation also roughly approximates Reference 6 data for dual AR coated cells for several hundred hours. The degradation after five years is not close to what Reference 6 extrapolated data predict, between 6 and 11 percent. We believe the degradation after five years is less than Reference 6 predictions because in-flight data on previous spacecraft have not shown such significant degradation. However, it is possible that these data are predicting correctly and that damage due to charged particle radiation is less than that generally computed and certainly less than that computed here [7].

We have assumed that micrometeoroids cause a two percent power loss and that this loss is linear over the five year life of the spacecraft. For purposes of evaluating power output in this paper, we have normalized to a no off-point condition. The impact of any localized torsional/ bending deflections of the blanket on power output are negligible. We have assumed that plasma causes a one percent power loss and that this loss is linear over the five year life of the spacecraft.
Table 2 predicts a 0.922 factor due to cell charged particle radiation. We have apportioned this to 0.958 in voltage and 0.962 in current. Over a five year interval, we have assumed that the voltage degrades per equation (2), where D represents days-in-orbit:

$$
1-0.0525^{*} \log \left(1+D^{*} 1.43^{*} 10^{14} / 1826^{\star} 2.7^{*} 10^{13}\right)
$$

and that the current degrades per equation (3):

$$
1-0.062 * \log \left(1+D * 5.02 * 10^{13} / 1826 * 1.62 * 10^{13}\right)
$$

These equations are of the form presented in equation 5-4 of Reference 7 for Isc. For the particular case of the Terra solar cell, the equation also works reasonably well for all currents and voltages.

Table 2 assumes no degradation due to uncertainty in measurement, although this could be present to a level of about $\pm 2 \%$. Table 2 assumes a degradation of $5.2 \%$ due to reliability calculations. In general, these losses should occur suddenly and at an unknown time due to solder joints or connector pins opening and probably will not occur at all. We have therefore not included these losses in the present evaluation. We have also not assumed a loss due to thermal cycling. Depending on the off-pointing condition and the seasonal sun intensity, the on-orbit measured sunlit cell temperature levels have ranged from 62 to $80^{\circ} \mathrm{C}$.

With these degradations included, the normalized on orbit current output of the Terra array is shown in Figure 10 as a percent of predicted output. At first glance it would appear that the variation from the expected output is rather large, both positive and negative. However, at least some of this variation is because the telemetry does not specify to what degree a partially transmitting circuit is turned on. With from eighteen to nineteen circuits (out of

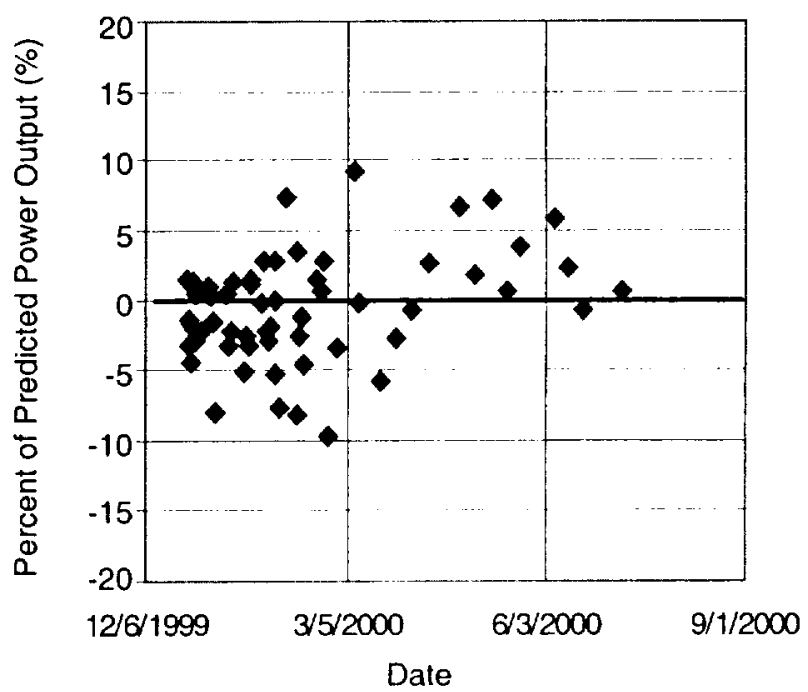

Fig. 10. Terra Solar Array On Orbit Power Output as a Percentage of Expected Output 
24) generally transmitting at this time, this means that we could obtain a current output that is up to $5.4 \%$ too high or $5.3 \%$ too low. Even with this allowance, the on-orbit data exceed or are less than what is predicted. This is attributed to differences in timing between telemetry acquisition of array current output and the number of transmitting shunts.

For information purposes, Figure 11 shows the predicted maximum output of the array over the 5-year Terra mission at a constant $70^{\circ} \mathrm{C}$ and zero off-pointing, without any allocation for reliability losses.

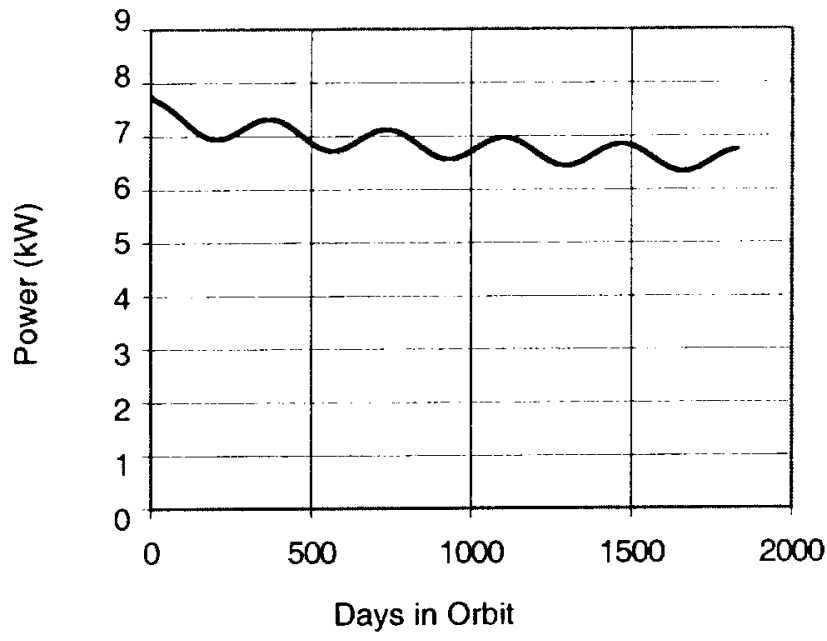

Fig. 11. Predicted Terra Solar Array On Orbit Maximum Power Point Output

\section{PERFORMANCE TRENDS}

Large area pulsed solar simulator (LAPSS) testing of the wing following electrostatic arc mitigation modifications to the solar cell circuits indicated a power output of about $8200 \mathrm{~W}$ at 158 Volts, at standard test conditions. Wing mass was about $185 \mathrm{~kg}$, excluding about $50 \mathrm{~kg}$ of components associated with the spacecraft power and attitude control subsystems (sun sensors, sequential shunt unit box, solar array drive interface harness) that were attached to the wing structure. EOL. performance at 127 Volts for the 5-year mission is estimated at $5100 \mathrm{~W}$ (specific power of $27.6 \mathrm{~W} / \mathrm{kg}$ ) based on the $8200 \mathrm{~W}$ LAPSS measurement and considering worst case EOL design factors, temperature and environmental degradation effects, sun intensity variation and sun-line off-pointing angles. If corrected to 10-year, near normal solar equinox conditions at the same $705 \mathrm{~km}$ polar orbit, the EOL power would be $5800 \mathrm{~W}(31.4 \mathrm{~W} / \mathrm{kg})$. With the same type of SJ $\mathrm{GaAs} / \mathrm{Ge}$ cells for a 10-year geosynchronous mission, the EOL power would be $5100 \mathrm{~W}(27.5 \mathrm{~W} / \mathrm{kg})$. With the expected availability of $26 \%$ triple junction $\mathrm{GaAs} / \mathrm{Ge}$ cells starting late-2000 with substantially better radiation stability than the earlier generation $S J$ cells, the EOL power output of the wing could be increased to about 9100 $W(48 \mathrm{~W} / \mathrm{kg})$ for a 10 -year LEO or GEO equinox mission.
Currently over 50 percent of the wing mass is allocated to non-power producing components (blanket housing structure/mechanisms, deployment mast subsystem, elevation hinge assembly, DEU, tiedown/release mechanism). Preliminary designs for different approaches to these structures/mechanisms hold the promise of reducing this mass by up to 40 percent, thereby reducing overall wing mass by $20 \%$ and increasing EOL specific power by $25 \%$. For blanket arrays for higher power missions, the specific power will increase at roughly the square root of the power ratio since most of the structures/mechanisms mass will not change, while the power-producing mass (blanket assembly, harness) would proportionally increase. Thus, for example, a 30 percent increase in EOL power would result in about a 15 percent increase in EOL specific power.

\section{REFERENCES}

[1] M. Herriage, R. Kurland, C. Faust, E. Gaddy, and D. Keys, "EOS AM-1 GaAs/Ge Flexible Blanket Solar Array," Vol. 1, Proceedings 31" IECEC, 1996, pp. 56-62.

[2] M. Herriage, et. Al., "EOS AM-1 GaAs/Ge Flexible Blanket Solar Array Verification Test Program Results," Vol. 1, Proceedings $32^{\text {nd }}$ IECEC, 1997, pp. 556-562.

[3] H. Schurig, M. Kruer, M. Levesque, E. Gaddy and W. Andiario, "Performance Testing of the $5 \mathrm{~kW}$ EOS AM-1 Flexible Blanket Solar Array Blanket," Vol. 1, Proceedings $32^{\text {nd }}$ IECEC, 1997, pp. 550-555.

[4] C. Hoeber, E. Robertson, I. Katz, V. Davis and D. Snyder, "Solar Array Augmented Electrostatic Discharge in GEO," AIAA Paper 98-1401, Feb 1998.

[5] S. Davis, R. Stillwell, W. Andiario, D. Snyder and I. Katz, "EOS AM-1 Solar Array ArC Mitigation Design," Paper No. 1999-01-2582, Proceeding 34 ${ }^{\text {th }}$ IECEC, 1999.

[6] A. Meulenberg, "UV Testing of Solar Cells: Effects of Antireflective Coating, Prior Irradiation, and UV Source," Proceedings of XII Space Photovoltaic Research and Technology Conference, 1992, pp. 268-279.

[7] B.E. Anspaugh, GaAs Solar Cell Radiation Handbook, JPL Publication 96-9, July 1996. 